\title{
Supporting Energy Management as a Cooperative Amateur Activity
}

\author{
Hanna Hasselqvist \\ Media Technology \& Interaction High-Performance Computing \& \\ Design, KTH Royal Institute of Visualization, KTH Royal Institute \\ Technology \\ Lindstedtsvägen 3 \\ 10044 Stockholm, Sweden \\ hannaha@kth.se \\ Cristian Bogdan \\ Media Technology \& Interaction \\ Design, KTH Royal Institute of \\ Technology \\ Lindstedtsvägen 3 \\ 10044 Stockholm, Sweden \\ cristi@kth.se

\section{Mario Romero} \\ of Technology \\ Lindstedtsvägen 3 \\ 10044 Stockholm, Sweden \\ marior@kth.se \\ Omar Shafqat \\ Energy Technology, KTH Royal \\ Institute of Technology \\ Brinellvägen 68 \\ 10044 Stockholm, Sweden \\ omars@kth.se
}

Permission to make digital or hard copies of part or all of this work for personal or classroom use is granted without fee provided that copies are not made or distributed for profit or commercial advantage and that copies bear this notice and the full citation on the first page. Copyrights for third-party components of this work must be honored. For all other uses, contact the Owner/Author.

Copyright is held by the owner/author(s).

CHI'15 Extended Abstracts, Apr 18-23, 2015, Seoul, Republic of Korea ACM $978-1-4503-3146-3 / 15 / 04$

http://dx.doi.org/10.1145/2702613.2732724

\begin{abstract}
There is increasing concern regarding current energy feedback approaches as they focus on the individual level, and mostly on household electricity, while the bulk of energy use often lies in heating and cooling. The aim is typically to change user routines, which does not bring a long-lasting impact. In our case study, we address these concerns for apartment buildings by looking at housing cooperatives, the dominant form of apartment ownership in the Nordic countries. These cooperatives manage the heating costs in common and therefore have a large potential for energy saving through long-lasting improvements and investments. We also emphasise the amateur nature of energy work within such cooperatives and consider the implications of our field study findings, interpreted through these amateur and cooperative perspectives, for the design of interactive artefacts.
\end{abstract}

\section{Author Keywords}

Eco-feedback; Energy-efficiency; Amateur; Energy cooperative

\section{ACM Classification Keywords}

H.5.m [Design]: Human Factors. 


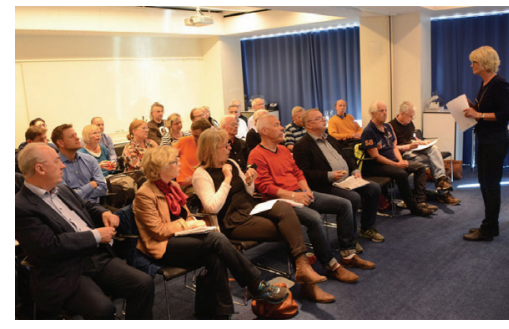

Figure 1. Meeting with the energy network (from [12], used with permission).

\section{Introduction}

Recently, the $\mathrm{HCI}$ community has expressed concern that the scope of research on persuasive technologies for sustainability is too narrow $[2,3,9,11]$. They question whether current approaches effectively contribute to long-term sustainable behaviours. One identified issue is the emphasis on changing individual behaviours without looking at change on other levels, which may produce greater impact [2]. A review of research on eco-feedback shows that the vast majority of tools aim to change routine behaviours rather than addressing one-time actions with long-term effects [6], even though one-time actions are claimed to have higher energy reduction potential [7]. Eco-feedback, as an approach to change individual behaviours, is also questioned. It does not work for everyone to rationally manage their everyday practises based on such feedback [11]. Current EU funded research projects are criticised for taking similar feedback approaches, despite the few known successful examples [3]. There are also concerns about energy feedback not addressing people's different stages of motivation [8]. A recent Swedish study of an energy feedback tool showed reductions in energy use only for highly motivated households [10].

Reviews of energy and eco-feedback technologies conclude that there is strong focus on residential electricity use $[9,6]$. Electricity is however just one part of a building's energy use. For Swedish apartments, only about $20 \%$ of the energy use is for household electricity and around $75 \%$ is used for heating and hot water [5]. Many issues related to energy for heating and hot water cannot be addressed by individual households, but have to be dealt with on a building level and managed by the building owner. This may lead to tensions between owners and residents, which have been studied by [4].

Our study focuses on apartment buildings owned by housing cooperatives, which we believe make an interesting case in moving beyond individual behaviours and addressing collective energy issues with a significant reduction potential. In Sweden, everybody who buys an apartment also joins a housing cooperative. The cooperative owns the building and annually elects a board to be in charge of the finances and maintenance of the building. Board membership is a voluntary commitment with no or little economic compensation and it does not require any specific skills or knowledge.

As part of a longer design process, we have studied housing cooperatives in a new residential area Hammarby Sjöstad in Stockholm, Sweden. The cooperatives are involved in a local initiative called HS2020, which has set up an energy network of volunteer representatives (energy managers) from the boards of the around 40 associated housing cooperatives. These volunteer energy managers, who are in charge of buildings with an average of about 40 apartments each, are in most cases amateurs.

Previously, we found that an important motivator of amateur work is the challenge it presents [1]. Amateur work is fundamentally social, with learning from peers being especially important in short-term membership settings, which is typically the case in the housing cooperative boards. In this social context, pioneering of new kinds of achievements and review of the peer achievements are critical components of the rewards associated with amateur challenges. 


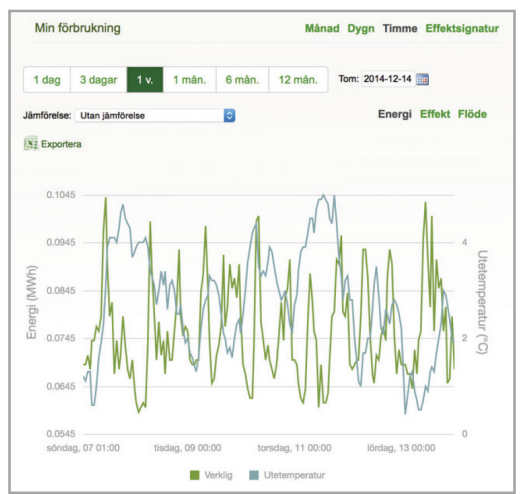

Figure 2. Screen shot of online information from the energy provider.

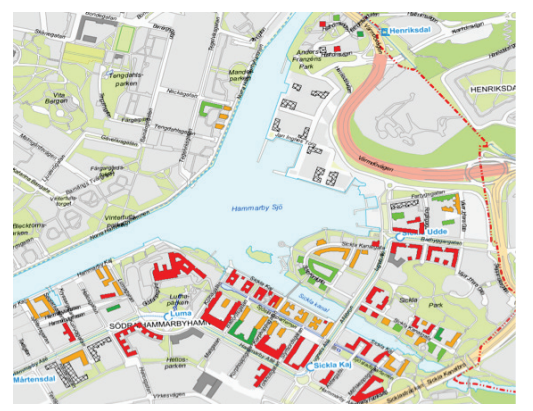

Figure 3. Visualisation of energy performance of buildings (from [12], used with permission).
In this work-in-progress, we present a housing cooperative perspective on energy management and the challenges that drive such amateur energy communities. We propose a new design space for energy tools in such settings and we outline a number of opportunities for interaction design to support discussions, decisions, and actions in amateur community energy management.

\section{Case Study: Energy Management in Housing \\ Cooperatives}

We have observed the energy work in Hammarby Sjöstad during one year by joining 9 energy meetings with HS2020 and collecting reports from related projects in the area. To receive more specific input we have carried out an energy simulation workshop with HS2020, documented the energy systems in the buildings, met with a facility management company that is active in the area, and held 2 group interviews with housing cooperative representatives. We have analysed our notes from the meetings, observations, workshop and interviews, together with information material and meeting minutes distributed by meeting organisers. In the analysis we identified a number of themes relevant for understanding the possibilities and challenges of housing cooperative energy management.

Current Forms of Energy Feedback

HS2020's goal is that all housing cooperatives should have an energy use below $100 \mathrm{kWh} / \mathrm{m}^{2}$ per year. This includes heating and hot water, provided by district heating, and facilities electricity. Currently the energy use in the area ranges from $55 \mathrm{kWh} / \mathrm{m}^{2}$ to 185 $\mathrm{kWh} / \mathrm{m}^{2}$, with an average of $118 \mathrm{kWh} / \mathrm{m}^{2}$ [12]. Many housing cooperatives have decided on individual goals to adapt the challenge level to their current situation.
The housing cooperatives can get information online about the building's hourly and aggregated use of district heating and facilities electricity from the provider. This tool (see Figure 2) is however only accessible for members of the board who have the necessary login information. Other members of a housing cooperative can follow the costs related to energy use in the cooperative's annual report, but do not get any other feedback on the collective energy use.

To compare housing cooperatives to each other, HS2020 created a static map-based visualisation of energy use (see Figure 3 ) with data from the legallyrequired energy declarations comprising information about the building's energy performance. This is a first step in comparing buildings but the declarations, which are only updated every ten years, are not particularly accurate. The energy managers we interviewed indicated that they would like to have better ways of comparing the energy use. They did not see any problem with sharing energy data on a building level openly. They rather saw benefits such as triggering improvements and engaging also ordinary housing cooperative members in energy matters.

From our amateur and cooperative perspective on energy, we can reflect that the current forms of energy feedback do not make energy sufficiently visible to allow for peer learning, review of peer achievements, or assessment of how well the energy saving challenge is addressed.

Energy Amateurs and Professionals

As for many amateurs, being part of the board and the energy network is a learning process. It is however 


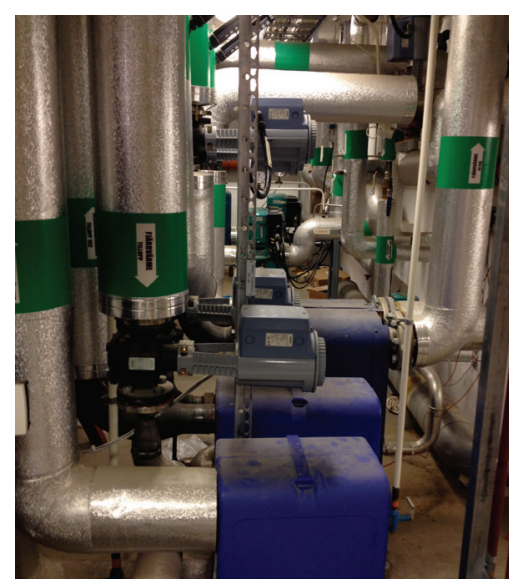

Figure 4. Energy system in the basement of one of the housing cooperatives. difficult to keep the knowledge in the cooperatives since board members change almost every year. As a consequence energy systems in the buildings are forgotten and become inefficient.

Amateurs are often in contact with and learn from professionals. In our case, there are on-going trials with facility management companies on target-driven energy management, whereby housing cooperatives buy expert knowledge that helps them optimise their energy systems. One housing cooperative report that its district heating costs were reduced by $21 \%$ using this approach. There is however no guarantee that all housing cooperatives would save money, since the cost for hiring the company might be higher than what can be saved. Some of the housing cooperatives also have bad experiences of being cheated by energy management companies and are now hesitant to take any risks.

Energy Issues and Savings Potential

The scope of the energy challenge for the amateurs is wide as there are many types of actions that can be taken to increase the energy efficiency in Hammarby Sjöstad. Some buildings were not as efficient as planned, with e.g. inadequate insulation of hot water pipes. There is also potential to invest in technology such as heat pumps for heat recovery to reduce heat demand. Another, lower-cost action is to optimise and maintain the current systems in the buildings. Energy audits have shown examples of ventilation systems with incorrect settings, ventilation filters that need to be replaced, unnecessary heating of outdoor areas all year around, and light sensors that do not work properly. Actions of people in the households can also affect the energy systems negatively, without the board necessarily noticing. One example is a household that put a piece of cloth in the ventilation outlet because it was considered to be too noisy. In some cases the energy audits have led to improvements but there are also cases where housing cooperatives still have not made any changes, not even simple and low-cost actions have been implemented. The energy auditor who has carried out the audits estimate that the buildings' overuse of energy varies from $10 \%$ to $50 \%$.

Collective Decision-Making

The cooperative aspects of energy management are apparent in the decision-making structures. District heating costs for a housing cooperative with 60 apartments can be around $€ 100,000$ per year. Consequently, decisions and actions that impact the energy use matter from an economic perspective. The boards can make decisions on investments up to a certain cost-level, which is set individually by each cooperative. For more expensive investments it is usually necessary to get approval at an annual meeting that all members are invited to.

Several of the energy managers state environmental reasons as their motivation to reducing energy use. At the same time they believe that few people would support costly actions with only environmental benefits - they also have to pay back financially. The boards need to be able to calculate the return on investment and communicate that to their members. Financing of such investments is usually achieved via loans, and people are generally hesitant about increasing their housing cooperative loans, since that may decrease the value of their apartment when it is time to sell.

Although these investments actually add value to the building, the impact of the investments is hidden from 

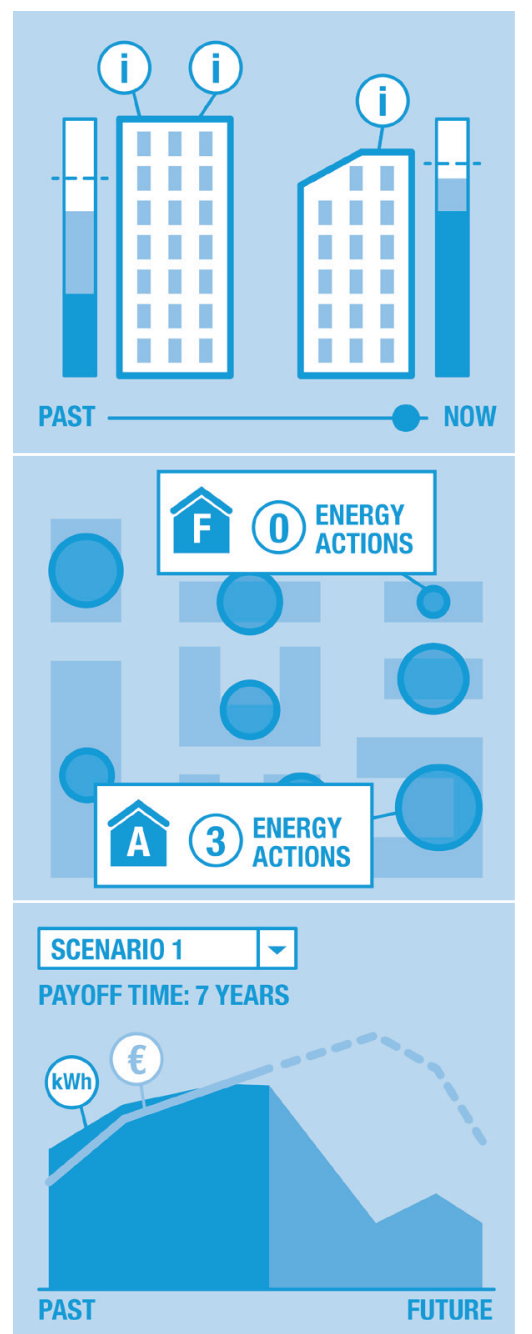

Figure 5. Tools should support housing cooperative energy learning, amateur motivation, and analysis and decision-making. potential buyers who only see the loans and a possibly out-dated energy declaration.

\section{Design Opportunities}

We identified a number of opportunities that aim to support housing cooperatives with amateur energy management in reducing their energy use. Such design interventions may also help other housing cooperatives that do not benefit from a network of energy managers like HS2020.

\section{Housing Cooperative Energy Learning}

Learning is essential in amateur settings [1]. Tools for energy amateur learning can facilitate the introduction of new board members and energy managers within a housing cooperative, mitigating the loss of knowledge when members leave. Another opportunity is to provide support for peer learning between the amateurs in different housing cooperatives. Tools can present information about energy actions taken by the cooperatives together with visualisations of their impact on energy use. This can be extended to include housing cooperatives outside of the local community that may have no local knowledge or network to rely on.

Energy Amateur Motivation

Openly visualising energy use at a housing cooperative level can create a sense of competition between housing cooperatives. This may motivate energy managers to address their energy amateur challenges and make pioneering energy actions more visible. In this way, energy managers and boards, as well as members of housing cooperatives, have an opportunity to feel proud of their accomplishments. Shared energy data also opens up for peer review of the housing cooperatives' energy work. Housing cooperative members can encourage boards to take action and the cooperative can become more competent to monitor the work of energy professionals. Engagement of the housing cooperative members is also important to secure that there are people who are willing to volunteer as energy managers in the future.

Analysis and Decision-Making in Housing Cooperatives Historical energy data and information about energy actions of the own housing cooperative and similar cooperatives provide a strong basis for analyses. Support for amateurs to analyse what actions to take in the future and to estimate costs and payoff time is particularly interesting. Tools can also support the next step of making decisions about actions and investments within boards as well as by all members of a housing cooperative. Another opportunity to prevent unnecessary energy use is to make it easier for housing cooperatives to identify when the energy systems are not working properly and when it is suitable and costeffective to request professional advice.

\section{Discussion and Future Work}

There is a strong focus on energy management in the context we have studied. While such an approach has been criticised for projects targeting individual

behaviours $[11,3]$, we believe energy management can still play an important role for housing cooperatives. In contrast to individual energy management that aims to change daily energy-related activities, housing cooperative energy management targets single interventions with long-lasting effects. Although the focus is on energy management, the support we envision is very different from classic energy feedback tools. Energy feedback should be linked to housing cooperatives' energy-reduction actions, there should be 
learning support for amateurs who serve the community for short time spans, and support for communication between different types of actors.

One way to summarise the design space we have charted is a replacement of the current, public but seldom-updated documents of the housing cooperatives with modern visualisations of past, current, and possible future energy situations. We believe that sharing such tools between housing cooperatives, between the board and ordinary members, and between energy amateurs and professionals, will facilitate activation of members with energy matters, as well as amateur learning and peer review. It will also make the value of energy investments and continuous optimisation apparent to prospective buyers, and consequently increase the incentives for the housing cooperatives to take energy reduction actions. Our next step is to create and test concepts, within this design space, together with various types of housing cooperatives

\section{Acknowledgements}

This work has been supported by EU FP7 programme through the project CIVIS (no 608774) and the Swedish STandUP for Energy Initiative. The authors are also grateful to the housing cooperatives and volunteers in HS2020.

\section{References}

[1] Bogdan, C. and Bowers, J. Tuning In: Challenging Design for Communities through a Field Study of Radio Amateurs. In C. Steinfield, B.T. Pentland, M. Ackerman and N. Contractor, eds., Communities and Technologies 2007. Springer, London, 2007, pp 439-461.

[2] Brynjarsdottir, H., Håkansson, M., Pierce, J., Baumer, E., Disalvo, C., and Sengers, P. Sustainably
Unpersuaded: How Persuasion Narrows Our Vision of Sustainability. Proc. CHI 2012, ACM (2012), 947-956.

[3] Cakici, B. and Bylund, M. Changing Behaviour to Save Energy: ICT-Based Surveillance for a Low-Carbon Economy in the Seventh Framework Programme. Proc. ICT4S 2014, (2014), 165-170.

[4] Dillahunt, T., Mankoff, J., and Paulos, E.

Understanding conflict between landlords and tenants: implications for energy sensing and feedback. Proc. Ubicomp 2010, (2010), 149-158.

[5] Eon. Har du normal elförbrukning?

http://www.eon.se/privatkund/Energieffektivisering/en ergiradgivning/normal-elforbrukning/.

[6] Froehlich, J., Findlater, L., and Landay, J. The Design of Eco-Feedback Technology. Proc. CHI 2010, ACM (2010).

[7] Gardner, G.T. and Stern, P.C. The Short List: The Most Effective Actions U.S. Households Can Take to Curb Climate Change. Environment: Science and Policy for Sustainable Development 50, 5 (2008), 12-25.

[8] He, H.A., Greenberg, S., and Huang, E.M. One Size Does Not Fit All: Applying the Transtheoretical Model to Energy Feedback Technology Design. Proc. CHI 2010, ACM (2010), 927-936.

[9] Pierce, J. and Paulos, E. Beyond energy monitors: interaction, energy, and emerging energy systems. Proc. CHI 2012, ACM (2012), 665-674.

[10] Selvefors, A., Karlsson, I.C.M., and Rahe, U. Use and Adoption of Interactive Energy Feedback Systems. Proc. IASDR 2013, (2013), 1771-1782.

[11] Strengers, Y. Smart Energy in Everyday Life: Are You Designing for Resource Man? Interactions, (2014), 24-31.

[12] Wintzell, H., Larsson, A., and Ociansson, W. Under 100 - att lyckas med energi i Hammarby Sjöstad. 2013. http://hs2020.se/wp-content/uploads/2013/12/under100.pdf 